\title{
Paragonimiasis Reemergence in Nigeria: Predisposing Factors and Recommendations for Early Intervention and Everlasting Eradication
}

\author{
Reginald A. Eke, ${ }^{1}$ Udochi M. Nwosu, ${ }^{2}$ Ezinne E. Enwereji, ${ }^{2}$ and Chima V. Emerole ${ }^{3}$ \\ ${ }^{1}$ Department of Public Health Medicine, Abia State University Teaching Hospital, C/o P.O. Box 3309, Aba, Nigeria \\ ${ }^{2}$ Department of Nursing Sciences, Abia State University, Uturu, Abia State, Nigeria \\ ${ }^{3}$ Department of Health Sciences, Federal University of Technology, Owerri, Imo State, Nigeria
}

Correspondence should be addressed to Reginald A. Eke; demregi@yahoo.com

Received 30 July 2012; Accepted 6 September 2012

Academic Editors: C.-K. Fan and M. Ramharter

Copyright (C) 2013 Reginald A. Eke et al. This is an open access article distributed under the Creative Commons Attribution License, which permits unrestricted use, distribution, and reproduction in any medium, provided the original work is properly cited.

\begin{abstract}
Effective paragonimiasis eradication programme in Nigeria eradicated the once endemic disease and no case was reported from 1980 to 2007. The first reported reemergence case was in 2007 and five more cases till January 2011 when this study was undertaken. This study is to determine the pre-disposing factors for the reemergence. The factors will help plan a sustainable long lasting and hopefully everlasting eradication programme. 2760 households from the identified twelve villages with the endemic disease were systematically selected. Pretested questionnaires were interviewer administered to the head of each of the selected household. The data collected were analyzed quantitatively and qualitatively. The pre-disposing factors that precipitated the reemergence of the disease included low level of awareness of the disease by the entire populace including the health workers. This included the causative agent, the mode of transmission, and control; conservative cultural habits of preparing crab meal; eating improperly cooked crab and also insanitary disposal of faeces and sputum. A holistic eradication programme should be planned to have sustained activities that will usher in everlasting disease-free area. The programme should involve all people, policy makers, health workers, and the entire populace, taking care of peculiarities of the peoples habits.
\end{abstract}

\section{Introduction}

Reemergence of a disease came to limelight on the international scene when a bold attempt was made to eradicate malaria in Siri Lanka (then Ceylon) many decades ago [1]. The resurgence of malaria hit the headlines in health fora at various times. Ever since various attempts have failed to produce lasting solutions after an attempted eradication programme of many diseases. This paper focuses on reemergence of paragonimiasis, a lung-fluke, food-borne zoonotic disease spread across the world. Paragonimiasis occurs in East and South East Asia, West Africa, and Central and South America [2]. The causative agent of this disease in man is Paragonimus metacercariae of 10 various identified species. The species infecting man include $P$. uterobilateralis and $P$. africanus in Nigeria, West Africa. Other species infect man elsewhere in the world. The paragonimiasis agent goes through a circle of transmission from man or various crab eating carnivorous mammals like dogs to snails of several genera and then to fresh water crustacean as metacercariae infect crab eating carnivorous animals as their natural reservoir of the Paragonimus species. It is to be noted that species in any natural reservoir may infect any other natural reservoir as in the case of $P$. uterobilateralis which was formally known to be a parasite of dog in Cameroun and of mangoose and bush rats in Liberia but eventually became a parasite of man in Nigeria [3-8].

Reemergence of paragonimiasis in Japan and Nigeria had been well discussed in recent times. The picture of endemicity of paragonimiasis in Miyazaki-Prefecture, Japan, before 1950, had been well documented [9]. After the 1950-1960 mass screening and prevention campaign by the Local Government, the disease drastically decreased. In the 1970s paragonimiasis was considered disease of the past in 
TABLE 1: Knowledge/awareness of paragonimiasis by age $(n=400)$.

\begin{tabular}{lcc}
\hline Age group & Aware & Not aware \\
\hline $25-35$ years & $0 /(0 \%)$ & $168(100 \%)$ \\
$36-46$ years & $13(3.25 \%)$ & $88(22 \%)$ \\
47 and above years & $82(20.5 \%)$ & $49(12.25 \%)$ \\
\hline Total & $95(23.75 \%)$ & $305(76.2 \%)$ \\
\hline
\end{tabular}

TABLE 2: Respondent's reasons for eating crab $(n=400)$.

\begin{tabular}{lcc}
\hline Reasons & Frequency & Percent \\
\hline Culturally acceptable food & 400 & $100 \%$ \\
Financially affordable & 392 & $98 \%$ \\
Readily available & 368 & $92 \%$ \\
It is our cultural delicacy & 400 & $100 \%$ \\
\hline
\end{tabular}

Miyazaki and other endemic areas in Japan. From late 1980s new case began to emerge sporadically in these previously endemic areas.

The situation in Nigeria showed a similar trend of events. Endmicity of the disease was recorded as from 1964 [58, 10]. Civil war in Nigeria (1968-1970) which caused a collapse in socioeconomic indices helped to make the disease a public health concern with very many cases of the disease in Nigeria. Following well-planned efficient and effective programme at the end of the war in Nigeria the disease was reported to be eradicated by 1980 . No case of paragonimiasis for treatment was reported from 1980 to September 2007. However, reemergence of the disease was reported in October 2007 [10]. Since 2007 to date this scenario of reemergence in Nigeria is like that reported in Japan. If nothing is done in Nigeria the disease reemergence will become a serious public health problem.

There is therefore a great need to initiate this study to determine pre-disposing factors that precipiated the reemergence of the disease in Nigeria. It is noted that the recommendations to be made here, will help the policy makers and health workers plan efficient and effective eradication programme that will usher in everlasting eradication of the disease. The experience gained here will help policy makers and the health worker to successfully treat disease reemergence anywhere in the world. The program should take into consideration the society's peculiarities in the factors identified.

\section{Methodology}

A cross-sectional study was carried out in the twelve villages along Imo, River Bank in Onu Imo Local Government Area of Imo State, Nigeria. These villages are in the endemic areas of paragonimiasis. The River Bank is the breeding place of crabs infested with metacercariae of Paragonimus uterobilateralis.

A sampling frame of each of the twelve villages was made by enumerating all the households within the villages. A population of 2760 households was recorded. A sample size of 400 households was calculated using Lutz' formula of $n=$ $z^{2} P q / d^{2}$.
TABLE 3: Identified cultural methods for preparing crab meal $(n=$ 400).

\begin{tabular}{lcc}
\hline Methods & Frequency & Percent \\
\hline Roasting/drying crab & 344 & $86 \%$ \\
Boiling and grinding crab as soup ingredient & 400 & $100 \%$ \\
Eating crab raw with alcohol & 400 & $100 \%$ \\
\hline
\end{tabular}

Selection of the 400 households out of the population of 2760 was by systematic sampling method using a sampling interval of seven. Data were collected from household interview using the questionnaire and review of health facilities record books. The reliability and validity of the questionnaire were ensured through vetting committee of health experts and also through a pretest of the questionnaire.

A total of 400 copies of the questionnaire was interviewer administered. An interactive discussion with the health providers at the health center was held in order to ascertain their level of awareness about paragonimiasis: index of suspicion and laboratory diagnosis of the disease. Data collected were analyzed quantitatively and qualitatively. Permission to carry out the survey was sought and obtained from the village heads and also from the individual respondents before administering the questionnaire on them. Data collected were handled in strict confidence.

\section{Result}

Table 1 shows that age was statistically significant in influencing knowledge and awareness of paragonimiasis among respondents $(P<0.005)$. About $23.75 \%$ respondents were aware of the disease. However no body was aware of paragonimiasis amongst the younger age group 25-35 years. Generally, younger age groups (25-46 years) were more ignorant about paragonimiasis in Nigeria than the elderly age group ( 47 years above). About $100 \%$ of respondents indicated that cultural acceptability of crabs as the people's delicacy was the strongest driving force for eating crabs, while ready availability of crabs in surrounding bushes and in their river at a cost every family can afford added reasons for eating crabs (Table 2).

Table 3 shows identified cultural methods for preparing crab meal that contributed to reemergence of paragonimiasis in the study area. About 95\% of the people eat uncooked crab with either alcohol, red pepper sauce, or with vinegar. Some $86 \%$ of the natives roasted or dried crabs and served it along African salad and Spinach made from oil bean seed and Amaranthus leaves, respectively. This delicacy is served mostly during traditional festivals. Generally $100 \%$ of people ground boiled crabs for short time as part of soup ingredients.

Table 4 shows that about $73 \%$ of the people did not wash ultensils (knife, mortar, and piston) used in preparing crab meal before using same ultensils in preparing other meals. This created great chances or possibilities of mechanical transporting metacercariae from one crab meal to other meals.

Table 5 shows that about $86.75 \%$ of people disposed excreta into river and near-by bushes around the homes, 
TABLE 4: Habit towards washing of utensils after crab meal preparation.

\begin{tabular}{lcc}
\hline Habit & Number & Percent \\
\hline Wash utensils after crab meal preparation & 108 & $27 \%$ \\
Do not wash utensil after crab meal preparation & 292 & $73 \%$ \\
\hline Total & 400 & $100 \%$ \\
\hline
\end{tabular}

while sputum was generally disposed in the immediate environment/outside. This implied that a greater number of Paragonimus uterobilateralis eggs were constantly being discharged into the river and bushes where appropriate mollusces breed.

The interactive discussions with the health workers showed that health workers at the health centers were not aware of paragonimiasis. Not even one paragonimiasis had been suspected or diagnosed in the health centers by the health workers, since that disease eradication exercise thirty years ago. Low index of suspicion of diagnosis of paragonimiasis had kept the reemergence unnoticed. All cases of cough and haemoptysis or rusty sputum had been investigated for a possible of pulmonary tuberculosis or HIV without the inclusion of paragonimiasis in the differential diagnosis.

\section{Discussion}

Evidence abounds of paragonimiasis reemergences in areas where it had been eradicated. In Japan, Maruyama et al. [11] and Nawa [12] have reported reemergence of paragonimiasis in areas where it was previously declared eradicated. In Nigeria, Enwereji and Eke [10] have also reported the reemergence of paragonimiasis. There is a worrying indication of this disease spreading into areas following its reappearance. The reemergence elsewhere when it occurs shows that the circle of transmission of this disease is closed. The new move here is directed towards identifying the determinant factors including cultural norms of the people that contribute to the reemergence in order to plan a sustainable eradication programme.

The fact that the younger age group, 25 to 45 years, was less knowledgeable about paragonimiasis mode of transmission, prevention, and control than the older age group of 47 years and above shows that most of them had not been born at the time of the disease eradication in Nigeria. The few born at that time were about 6 years old and so were too young to comprehend and use the eradication lessons learnt at that time. The breakdown shows that the discontinuation of the preventive and control activities after eradication contributed to the group being less apprehensive of paragonimiasis. The custom of eating crabs as a delicacy in Tables 2 and 3 created the avenue for disease reemergence.

Enwereji and Eke [10] argued that as long as the chain of transmission was broken and later became closed, the disease would certainly reemerge. Nawa [12] had earlier asserted that breaking circle of transmission only to close it up later caused reemergence of paragonimiasis in Japan. The unhygienic habit of not washing utensils properly after preparing crab meals in Table 4 also created another chance
TABLE 5: Cultural habit of disposing excreta and sputum $(n=400)$.

\begin{tabular}{|c|c|c|}
\hline Habit & Number & Percent \\
\hline $\begin{array}{l}\text { Dispose excreta inside river/surrounding } \\
\text { bushes }\end{array}$ & 347 & $86.75 \%$ \\
\hline Dispose excreta inside latrine & 53 & $13.25 \%$ \\
\hline Dispose sputum inside handker & 7 & $1.75 \%$ \\
\hline $\begin{array}{l}\text { Dispose sputum in the immediate } \\
\text { environment/outside }\end{array}$ & 393 & $98.25 \%$ \\
\hline
\end{tabular}

of transmitting metacerariae from crabs to man. The present study identified cultural practices of preparing and eating crabs raw and the unhygienic habit of not washing utensils used in preparing crab meal as contributing factors to the reemergence of paragonimiasis in Nigeria. This finding is in keeping with the report of Lucas and Gilles [3] that infection can occur by eating uncooked crabs and crayfish and also when encysted cercaria are left on the knife or other utensils used in preparing crab meal.

The finding that there was insanitary disposal of excreta and sputum into Imo River and nearby bushes could have contributed to reemergence of paragonimiasis in Nigeria, tallies with the report of some authors $[3,8,13]$. There is a need to note that the transmission of paragonimiasis is maintained by feacal and sputum pollution of water in which the appropriate snails and vectors crustaceans breed.

Lack of awareness of paragonimiasis amongst the health workers at the health centers caused the low level of index of suspicion amongst them. Awareness of the disease would have made the health workers continue to have high index of suspicion of the disease and then confirm their suspicion by laboratory tests for cases of cough and haemoptysis which could have been caused by pulmonary paragonimiasis, in addition to pulmonary tuberculosis or HIV.

According to Shim et al. [14] variable paragonimiasis egg excretion of many patients can present negative stool result. Therefore negative test for paragonimiasis could be mistaken for tuberculosis or other diseases.

\section{Recommendation}

This study was undertaken to highlight the need for surveillance and to ensure that there is no reemergence. Based on the findings in this study, we recommend the following.

(1) The health authorities and the policy makers should be health educated on how to check a reemergence. This training will enable them to know what they are expected to do to achieve success of the programme.

(2) Health information of the disease should be done on regular basis and involve all people at village and community levels.

(3) Routine disease surveillances system and notification should be established to function as if they were put in place during the eradication programmes. 
(4) Diagnostic and treatment facilities' workers should be given periodic lectures, seminars, and workshops on the disease information.

(5) New diagnostic and treatment procedures like Antigen detection assay indentifield by [15] should be established by the relevant authorities to facilitate the disease diagnosis.

(6) People should be health educated on the consequences of eating partally cooked or uncooked crabs as delicacies. Therefore where crabs are the main source of protein intake, alternative but available and affordable protein substitute should be introduced.

With proper education on eradication of disease in place, effective and efficient surveillances program will be cost effective.

\section{References}

[1] J. M. Vinetz and R. H. Gilman, "Editorial: asymptomatic Plasmodium parasitemia and the ecology of malaria transmission," The American Journal of Tropical Medicine and Hygiene, vol. 66, no. 6, pp. 639-640, 2002.

[2] W. Peter and H. M. Gilles, Color Atlas of Tropical Medicine and Parasitology, LondonWolfe, Medicla Publications, 4th edition, 1977.

[3] A. O. Lucas and H. M. Gilles, Short Textbook of Public Health Medicine for the Tropics, Book Power, 4th edition, 2007.

[4] C. Nwokolo, "Paragonimiasis in Eastern Nigeria," The Journal of Tropical Medicine and Hygiene, vol. 67, pp. 1-4, 1964.

[5] C. Nwokolo, "Outbreak of paragonimiasis in Eastern Nigeria," The Lancet, vol. 1, no. 7740, pp. 32-33, 1972.

[6] C. Nwokolo, "Endemic paragonimiasis in Eastern Nigeria. Clinical features and epidemiology of the recent outbreak following the Nigerian civil war," Tropical and Geographical Medicine, vol. 24, no. 2, pp. 138-147, 1972.

[7] C. Nwokolo, "Endemic paragonimiasis in Africa," Bulletin of the World Health Organization, vol. 50, no. 6, pp. 569-571, 1974.

[8] J. Voelker and C. Nwokolo, "Human paragonimiasis in Eastern Nigeria caused by Paragonimus uterobilateralis," Zeitschrift für Tropenmedizin und Parasitologie, vol. 24, no. 3, pp. 323-328, 1973.

[9] Y. Nawa, "Re-emergence of paragonimiasis," Internal Medicine, vol. 39, no. 5, pp. 353-354, 2000.

[10] E. E. Enwereji and R. A. Eke, Re-Emergence of Paragonimiasis in Nigeria: A Case Report and Future Challenges, TAF Preventive Medicine Bulletin, Ankara, Turkey, 2010.

[11] H. Maruyama, S. Noda, and Y. Nawa, "Emerging problems of parasitic disease in Southern Kyushu," Japanese Journal of Parasitology, vol. 45, no. 3, pp. 192-1200, 1996.

[12] Y. Nawa, "Recent trends of paragonimiasis westermani in Miyazaki Prefecture, Japan," The Southeast Asian Journal of Tropical Medicine and Public Health, vol. 22, supplement, pp. 342-344, 1991.

[13] F. O. I. Arene, E. Ibanga, and J. E. Asor, "Epidemiology of paragonimiasis in Cross River basin, Nigeria: prevalence and intensity of infection due to Paragonimus uterobilateralis in Yakurr local government area," Public Health, vol. 112, no. 2, pp. 119-122, 1998.
[14] Y. S. Shim, S. Y. Cho, and Y. C. Han, "Pulmonary paragonimiasis: a Korean perspective," Seminars in Respiratory Medicine, vol. 12, no. 1, pp. 35-45, 1991.

[15] Y. Q. Zhang, Z. Y. Wu, W. Yan et al., "Detection of paragonimiasis circulating antigen in sera with mixed mono-cional antibodies by anti-body Sandwich-ELISA applied," Journal of Parasitic Disease, vol. 1, pp. 1-4, 1993. 


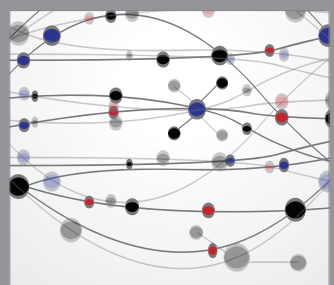

The Scientific World Journal
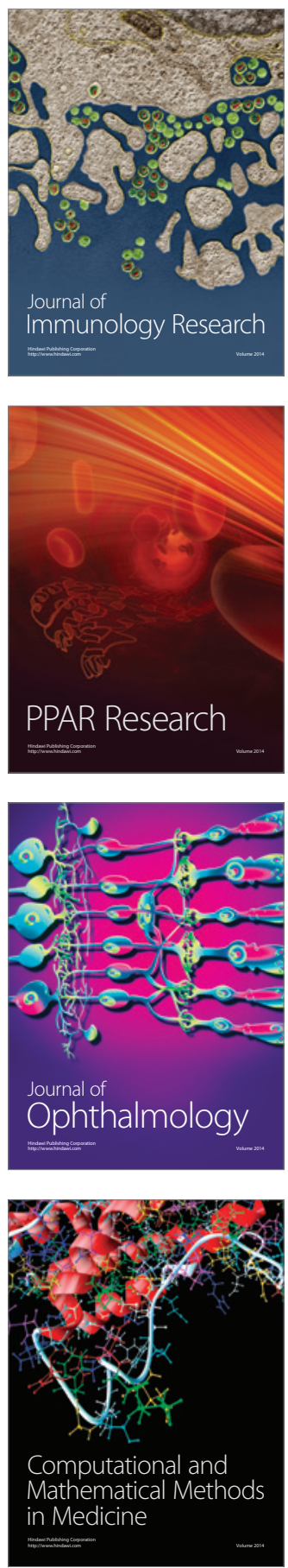

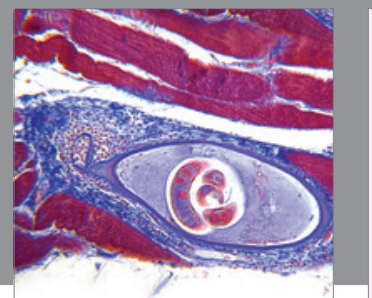

Gastroenterology

Research and Practice
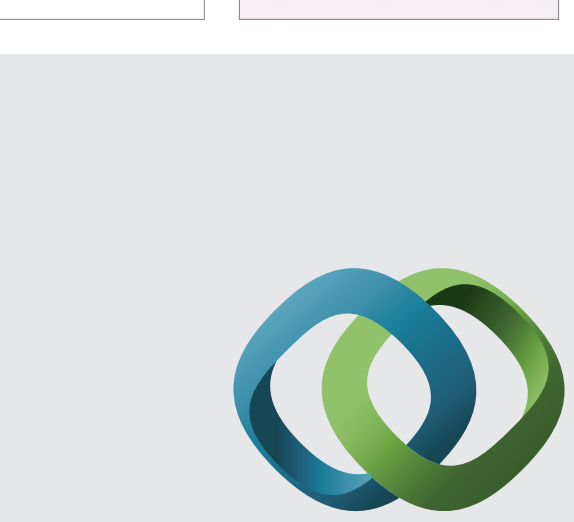

\section{Hindawi}

Submit your manuscripts at

http://www.hindawi.com
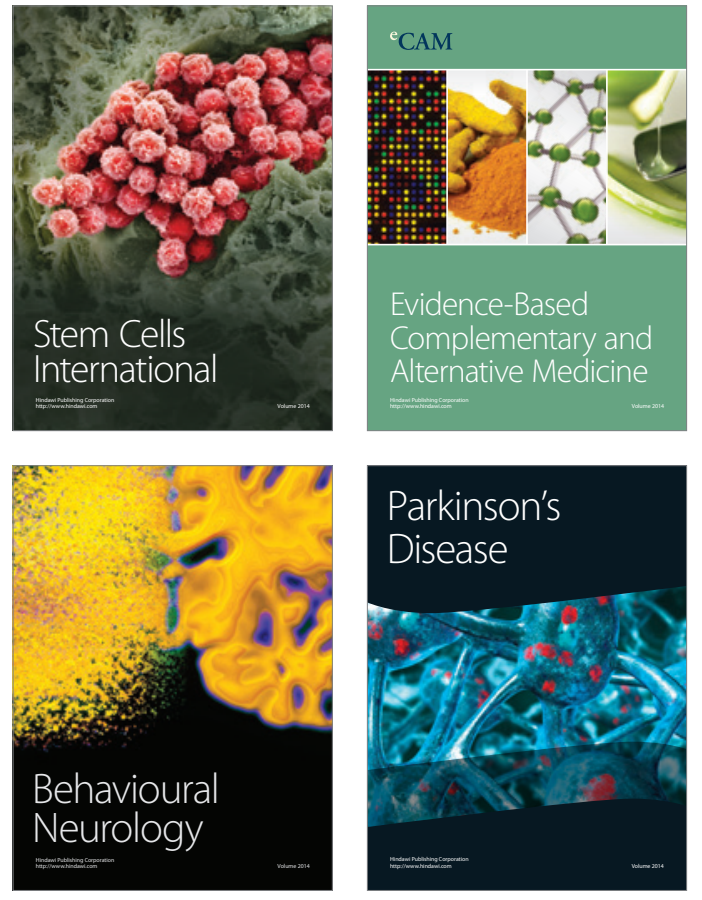
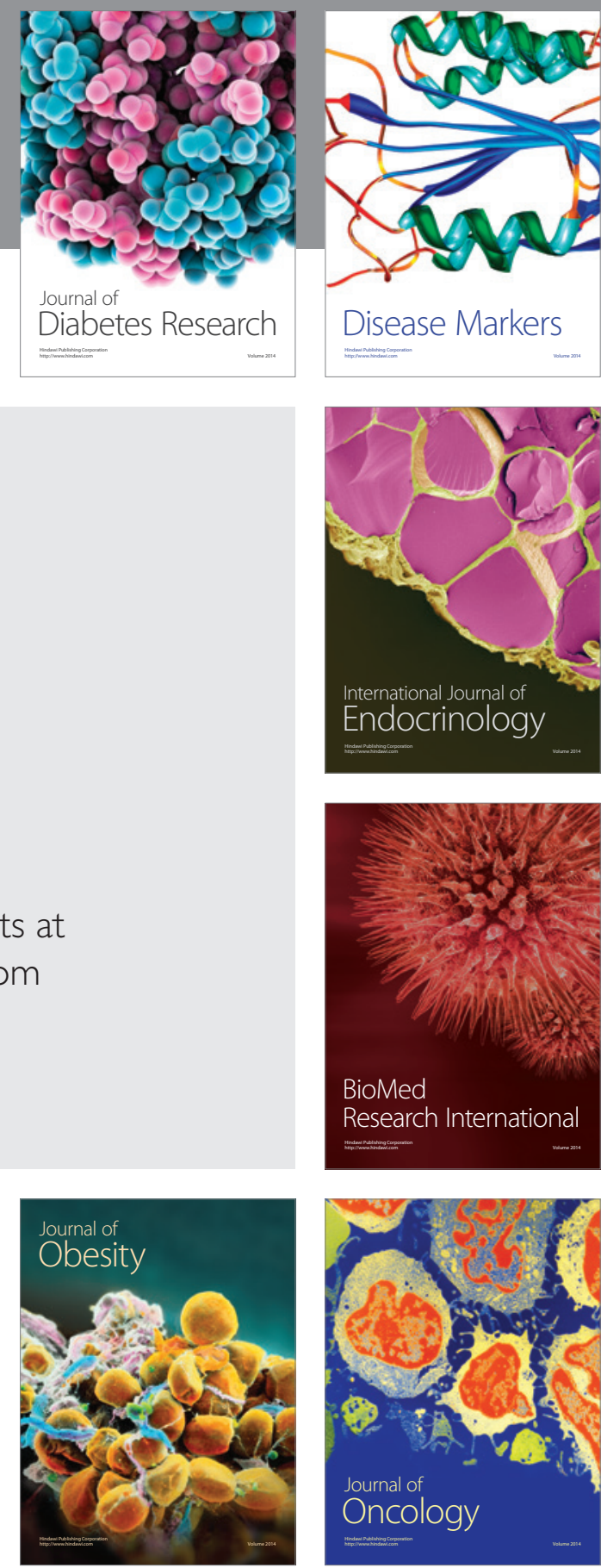

Disease Markers
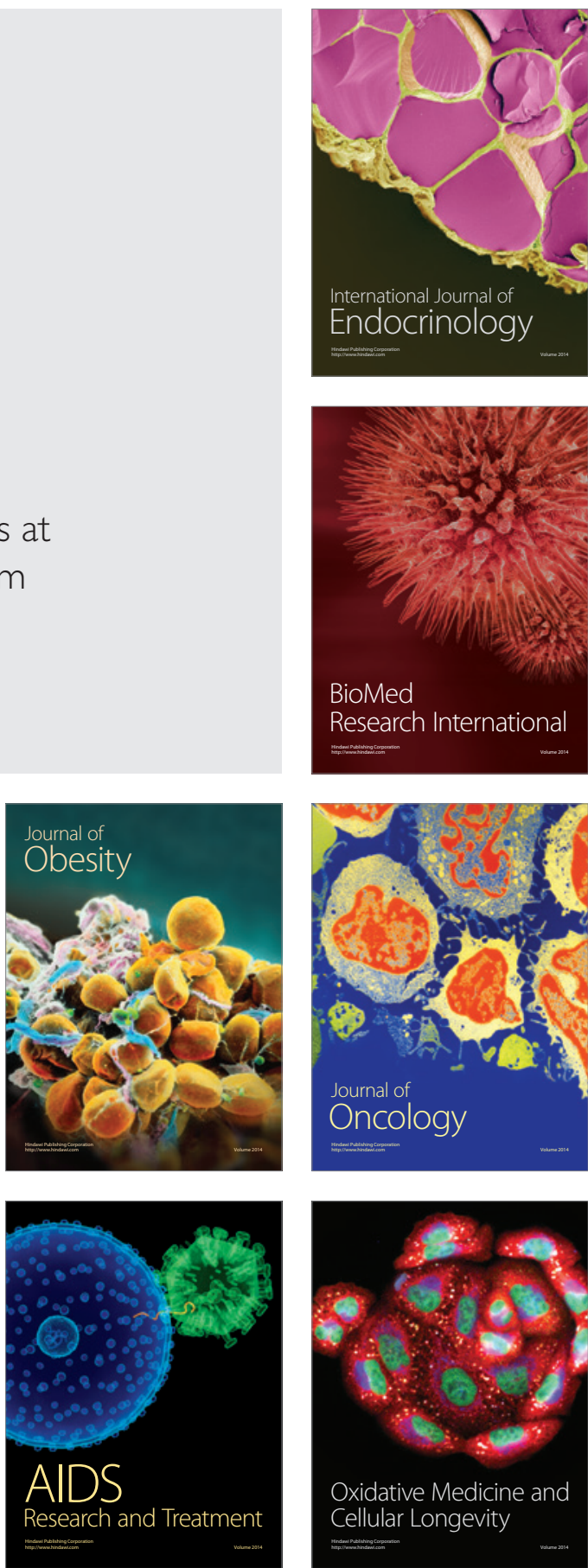